\title{
Comparison and evaluation of mechanistic rumen models
}

\author{
BY A. BANNINK, H. DE VISSER AND A. M. VAN VUUREN \\ DLO-Institute for Animal Science and Health, Department of Ruminant Nutrition, PO Box 65, \\ NL 8200 AB Lelystad, The Netherlands
}

(Received 9 September 1996 - Revised 20 February 1997 - Accepted 28 February 1997)

\begin{abstract}
Mechanistic rumen models of Baldwin (1995), Danfær (1990) and Dijkstra et al. (1992) were compared on identical inputs that were derived from trials with lactating dairy cows fed on grass herbage. Consistent differences were detected between models and between predicted and observed outputs. None of the models seemed to predict all nutrient flows best. The models particularly differed in the representation of microbial metabolism: degradation of insoluble substrate, fermentation of substrate into volatile fatty acids, and incorporation of substrate into microbial matter. Differences amongst models in the prediction of these processes compensated for each other and consequently all models predicted the duodenal flow of non- $\mathrm{NH}_{3} \mathrm{~N}$, microbial $\mathrm{N}$ and organic matter reasonably well. Large differences remained in the prediction of individual nutrient flows, however, and it was stressed that in order to enhance prediction of the profile of nutrient flows, the mechanisms of microbial metabolism need to be tested on their ability to describe the intraruminal transactions. However, this requires more-detailed information on individual nutrient flows and on the microbial or non-microbial origin of duodenal contents. Parameter inputs for physical and chemical feed properties were identified that are improperly defined in extant models or susceptible to error. The description of these feed characteristics needs to be developed further and become identifiable for a wide range of dietary conditions.
\end{abstract}

Rumen: Models: Lactation

Current research into the nutrition of lactating dairy cows focuses on the profile of nutrients absorbed from the digestive tract, on the partitioning of these nutrients in intermediary metabolism, and on the utilization of these nutrients for milk production and body tissues. However, when theories of dietary influences on nutrient partitioning and animal production are to be investigated, the effect of dietary factors on feed digestion and the profile of nutrients absorbed from the gastrointestinal tract needs to be defined. In particular, an understanding of rumen function is essential for estimating these nutrient flows, because the profile of nutrients can change dramatically due to events in the rumen.

Mathematical modelling is an important instrument for understanding and integrating knowledge (Baldwin, 1995). Detailed dynamic models that describe the mechanism of rumen function in cattle have been developed by Baldwin et al. (1987; BA), Danfær (1990; DA) and Dijkstra et al. (1992; DY). Although the BA and DA models are whole-animal models, in contrast to the DY model, the part that describes rumen function can easily be extracted in both cases because it is formulated as a separate module. Although the models have differing objectives and consequently apply different concepts and theories, all three models basically simulate the digestion, absorption and outflow of nutrients from the rumen. The model inputs required include daily feed intake, the composition and other characteristics of the feed, and several parameters describing rumen conditions. The BA model describes a mechanism to explain the rate at which nutrients become available for 
the micro-organisms by including a representation of particle dynamics and the physical relationships between particulate substrate and micro-organisms. The DA model describes several pools for the constituents of the single type of micro-organism represented, whereas the DY model is concerned with studying the interactions between distinct microbial groups and with a more detailed description of fermentation processes. Extensive evaluations, by comparing observed with predicted values, have been published for the DY model (Neal et al. 1992).

An essential step in the evolution of rumen modelling is to investigate whether specific aspects of rumen function are represented satisfactorily in extant models and to evaluate the importance of the different concepts and theories used in explaining observed rumen function quantitatively. However, an integral comparison between the BA, DA and DY models is hindered because, for example, differences in model behaviour appearing from previous evaluation studies are confounded by the use of different sets of evaluation data with each rumen model, or, extensive evaluations have not been published. To overcome such limitations in the present study, the BA, DA and DY models were evaluated and compared on the same observations of rumen function. The objective was to compare and evaluate the different concepts adopted in these models on inputs that correspond between models and coincide with experimental rumen conditions. Results of feeding trials with lactating dairy cows that provided almost all the required inputs and many data for evaluation of model predictions were used.

\section{MATERIALS AND METHODS}

\section{Selected data for evaluation}

Experiments of Van Vuuren et al. $(1992,1993)$ with lactating dairy cows, fed on fresh grass, were selected for the evaluation of model predictions. The experiments were selected because of the extensive determination of rumen kinetics from measurements of duodenal flows, rumen evacuations, in situ degradation characteristics, diet analyses and endproducts of fermentation (volatile fatty acids (VFA), $\mathrm{NH}_{3}$ and microbial matter). The available data provided almost all feed characteristics and parameter inputs that were required by the BA, DA and DY models. Considerable variation existed in these model inputs (Table 1) and in observed values on which model predictions were evaluated.

Animals were fed on freshly cut ryegrass ( $85 \%$ Lolium perenne), which accounted for at least half of the total diet. Models have not been evaluated on fresh grass before. Although the sum of the chemical fractions was less than $100 \%$ of total DM, the model inputs were not corrected because the composition of missing DM was not clear.

In the first experiment (Van Vuuren et al. 1993), the effect was studied of partial replacement of ryegrass herbage (diet 1) by maize meal plus hominy feed (diet 2) and sugarbeet pulp (diet 3) on rumen digestion and intestinal amino acids (AA) in lactating dairy cows. Ryegrass comprised 890,570 and $560 \mathrm{~g} / \mathrm{kg}$ total DM of diets 1,2 and 3 respectively, and DM intakes were $16.3,16.3$ and $16.5 \mathrm{~kg} / \mathrm{d}$ respectively, including $1.7 \mathrm{~kg}$ commercial concentrate/d. Sugarbeet pulp contains a considerable proportion of pectin which is highly degradable in the rumen but not identified by chemical feed analysis (Van Vuuren et al. 1993). This additional missing fraction compared with chemical analysis of the other experimental feedstuffs was corrected with an extra $80 \mathrm{~g}$ soluble carbohydrate $/ \mathrm{kg}$ DM intake in diet 3. Further, it was assumed that $25 \%$ of soluble $\mathrm{N}$ (e.g. nucleic acids and nitrate) was immediately hydrolysed to $\mathrm{NH}_{3}$ in the rumen (Goswami \& Willcox, 1969). Consequently, all remaining model inputs of feed $\mathrm{N}$ were considered to consist of amino acid $\mathrm{N}$ (AAN). Because the major part of soluble feed $\mathrm{N}$ was of herbage origin, these 
Table 1. Inputs to the models of Baldwin (1995; BA), Danfar (1990; DA) and Dijkstra et al. (1992; DY) for seven test diets

\begin{tabular}{|c|c|c|c|c|c|c|c|c|c|c|}
\hline Diet... & 1 & 2 & 3 & 4 & 5 & 6 & 7 & \multicolumn{3}{|c|}{ Model $\uparrow$} \\
\hline \multicolumn{11}{|c|}{ Chemical composition of diet ( $\mathrm{g} / \mathrm{kg} \mathrm{DM})$} \\
\hline $\mathrm{SC}$ & 146 & 104 & 190 & 164 & 174 & 146 & 193 & BA & DA & DY \\
\hline DST* & 6 & 121 & 18 & 4 & 3 & 4 & 3 & BA & DA & DY \\
\hline SST*t & 2 & 36 & 5 & 1 & 1 & 1 & 1 & BA & DA & DY \\
\hline NDF ${ }^{\top}$ & 409 & 351 & 407 & 373 & 397 & 406 & 333 & $\mathrm{BA}$ & $\mathrm{DA}$ & DY \\
\hline $\mathrm{DNDF}^{*}$ & 373 & 326 & 376 & 345 & 360 & 364 & 311 & $\ldots$ & DA & DY \\
\hline Lignin & 12 & 10 & 13 & 13 & 14 & 27 & 12 & BA & $\ldots$ & $\ldots$ \\
\hline $\mathbf{N}$ & 28.9 & $27 \cdot 1$ & 25.8 & $33 \cdot 6$ & 27.9 & $27 \cdot 1$ & 31.3 & BA & DA & DY \\
\hline $\mathrm{SN}^{*}$ & 5.6 & 8.5 & 6.5 & $16 \cdot 8$ & $12 \cdot 4$ & $10 \cdot 1$ & 14.0 & $\mathrm{BA}$ & $\ldots$ & DY \\
\hline $\mathbf{U N}^{*}$ & $1 \cdot 1$ & 1.2 & 1.4 & $1 \cdot 1$ & 1.4 & 1.6 & $1 \cdot 1$ & $\ldots$ & DA & DY \\
\hline $\mathrm{NH}_{3}$ & 1.4 & $2 \cdot 1$ & 1.6 & $4 \cdot 2$ & $3 \cdot 1$ & $2 \cdot 5$ & 3.5 & BA & DA & DY \\
\hline Lipid & 39 & 41 & 31 & 37 & 37 & 41 & 37 & $\mathbf{B A}$ & DA & DY \\
\hline \multicolumn{11}{|c|}{ Parameter inputs $\S$} \\
\hline Intake $(\mathrm{kg} / \mathrm{d})$ & $16 \cdot 2$ & $16 \cdot 3$ & $16 \cdot 5$ & $13 \cdot 3$ & $16 \cdot 8$ & 13.0 & $15 \cdot 2$ & BA & DA & DY \\
\hline$k d_{\mathrm{DNDF}}(/ \mathrm{d})^{*}$ & 1.25 & 1.56 & 1.65 & 1.41 & 1.24 & $1 \cdot 10$ & 1.64 & $\ldots$ & $\ldots$ & DY \\
\hline$k d_{\mathrm{DP}}(/ \mathrm{d})^{*}$ & 1.97 & 2.08 & 1.87 & $2 \cdot 12$ & $2 \cdot 17$ & 1.53 & $2 \cdot 14$ & $\ldots$ & $\ldots$ & DY \\
\hline$k d_{\mathrm{DST}}(/ \mathrm{d})^{*}$ & 3.00 & 2.71 & 3.00 & 3.00 & 3.00 & 3.00 & 3.00 & $\ldots$ & $\ldots$ & DY \\
\hline$k p_{\mathrm{LIQ}}(/ \mathrm{d})$ & 3.72 & 3.89 & 3.89 & 4.51 & $4 \cdot 13$ & 2.86 & 2.26 & BA & DA & DY \\
\hline$k p_{\mathrm{OM}}(/ \mathrm{d})$ & 0.77 & $1 \cdot 22$ & 0.94 & 0.79 & 0.82 & 0.58 & 0.58 & BA & DA & DY \\
\hline $\mathrm{pH}$ & $6 \cdot 14$ & $6 \cdot 16$ & $6 \cdot 15$ & $6 \cdot 63$ & $6 \cdot 12$ & 6.20 & $6 \cdot 13$ & $\mathrm{BA}$ & $\ldots$ & DY \\
\hline $\mathrm{pH}-\min$ & 5.78 & $5 \cdot 87$ & 5.86 & 6.40 & 5.90 & 6.00 & 5.95 & $\ldots$ & $\cdots$ & DY \\
\hline Tf63 (h) & 17.0 & 14.0 & $15 \cdot 5$ & 0.0 & 20.0 & 15.0 & $18 \cdot 0$ & $\ldots$ & $\ldots$ & DY \\
\hline Tf60 (h) & 5.0 & 4.5 & 4.5 & 0.0 & 4.0 & 2.0 & 4.0 & $\ldots$ & $\ldots$ & DY \\
\hline Vol (litres) & 64.5 & 53.8 & 57.7 & 54.6 & 64.0 & 67.8 & $72 \cdot 9$ & BA & DA & DY \\
\hline
\end{tabular}

SC, soluble carbohydrate; DST, insoluble, degradable starch; SST, soluble starch; NDF, neutral-detergent fibre; DNDF, degradable NDF; $\mathrm{SN}$, soluble nitrogen; UN, undegradable $\mathrm{N} ; k p_{\mathrm{LrQ}}$, fractional liquid passage rate; $k p_{\mathrm{OM}}$, fractional organic matter passage rate; $k d_{\mathrm{DNDF}}$, degradation rate NDF; $k d_{\mathrm{DP}}$, degradation rate protein; $k d_{\mathrm{DST}}$, degradation rate starch; $\mathrm{pH}$, mean $\mathrm{pH} ; \mathrm{pH}-\mathrm{min}$, minimum $\mathrm{pH}$; Tf63, time interval $\mathrm{pH}<6.3$; Tf60, time interval $\mathrm{pH}<6.0$; Vol, rumen non-dry matter.

* Value estimated from nylon bag incubations.

+ Indicates whether a model input is used (BA, DA or DY) or not used (...) in a model.

$¥$ With the exception of diet 2 , starch solubility was assumed to be $20 \%$.

$\S$ All remaining parameter inputs are described on pp. 566-567.

assumptions were applied to total diets. Rumen pool sizes and duodenal flows of microbial $\mathrm{N}(\mathrm{MN})$ were estimated with diaminopimelic acid (DAPA) as microbial marker (DAPA method). The microbial fraction in the duodenal flow of AAN was estimated with the observed fraction of $\mathrm{MN}$ in duodenal flow of non- $\mathrm{NH}_{3} \mathrm{~N}$ (NAN).

The second experiment (Van Vuuren et al. 1992) studied effects of $\mathrm{N}$ fertilization and season: 500 (diets 4 and 7) v. $275 \mathrm{~kg} \mathrm{~N} /$ ha per year (diets 5 and 6), harvested either in June-July (diets 4 and 5) or September-October (diets 6 and 7). DM intake varied between 13.0 and $16.8 \mathrm{~kg} / \mathrm{d}$ and included $1 \mathrm{~kg}$ commercial concentrate $/ \mathrm{d}$. The same assumptions were made about $\mathrm{N}$ inputs as for the first experiment. Microbial protein was quantified by two methods. First, the proportion of microbial AAN (MAAN) in the duodenal flow of total AAN was estimated from measured AA profiles in grass, isolated microbial matter and duodenal contents (AA profile method). Second, rumen pool size and duodenal flow of MN were estimated with the DAPA method (results not published). With both methods the observed microbial proportion was applied to estimate MN flow from the duodenal flow of NAN as well as MAAN flow from the duodenal flow of AAN. 


\section{Rumen models}

The BA, DA and DY models were written in the Continuous System Modeling Program (CSMP) (Speckhart \& Green, 1976). Simulations were performed with a fourth-order variable step length Runge-Kutta as integration method and with integration periods for the BA, DA and DY models of 20,50 and $20 \mathrm{~d}$ respectively, which proved to be sufficient to reach a stable steady-state solution in every condition. Models were evaluated and compared on their steady-state solution. Certain parameter inputs for the BA and DA models were not measured, although their value clearly depends on the diet fed.

$B A$ model. An updated version of the BA model was used (Baldwin, 1995). The experimental database delivered all required inputs for the BA model, except those for particle dynamics in the rumen. Although Baldwin et al. (1987) considered these parameter inputs to be variable, they used constants for the description of rumen particle dynamics: fractional outflow rates of small particles and fluid of $1.45 / \mathrm{d}$ and $3.5 / \mathrm{d}$ respectively, a fractional comminution rate of large particles of $4.5 / \mathrm{d}$, and little variation of the partitioning of ingested particles over the large and small particle pool (i.e. a particle size factor of 0.4 or 0.5 ). These constant parameter values resulted in little variation in predicted outflow rate of organic matter (OM) of 0.69 (SD 0.03)/d (results not shown). However, the observed fractional outflow rates of OM varied much more among diets: 0.81 (SD 0.20$) / d$. To account for such variation of particle dynamics in the present study, it was necessary to vary outflow rates of $\mathrm{OM}$ and liquid. Moreover, if observed values are used for particle dynamics with the DA and DY models, it is a prerequisite to use them also with the BA model for model comparison on identical inputs.

In the BA model, fractional outflow rate of particles only applies to the small-particle pool, whereas observed outflow rates of particulate $\mathrm{OM}$ apply to both small and large particles. Therefore, the observed fractional outflow rates of OM were corrected by the factor (total particle pool):(small particle pool). This correction is only valid with accurate prediction of the pool sizes of small and large particles in steady-state. To predict pool sizes, the input parameters of fractional comminution rate of large particles and particle size factor must be considered (Baldwin et al. 1987). However, these key parameters in model prediction were not measured and, therefore, appropriate estimates had to be made.

The comminution rate of large particles is formulated as a rumination factor $x$ the fractional comminution rate of large particles (Baldwin et al. 1987). In the BA model the rumination factor is 0.333 in steady-state. With a fractional comminution rate of $4.50 / \mathrm{d}$ this results in a comminution rate of $1.5 / \mathrm{d}$. Applying the corrected estimates of outflow rate of OM to the small-particle pool in the BA model, with 0.4 for the particle size factor and $4.5 / \mathrm{d}$ for the fractional comminution rate, resulted in large prediction errors. Second, these parameter values resulted in similar pool sizes for small and large particles, although experimental data (Poppi et al. 1981; Bosch, 1991) of rumen contents clearly show predominance of small particles $(72-81 \%)$ for the type of diets used in this study. Therefore, the fractional comminution rate and the particle size factor were reestimated.

Experimental estimates of the comminution rates of large particles range from 0.96 to 3.12/d (Woodford \& Murphy, 1988). Although techniques used in several studies with lactating dairy cows were different, reported estimates affirm such a large range (McLeod \& Minson, 1988; Woodford \& Murphy, 1988; Bosch, 1991). Sensitivity analysis (Baldwin et al. 1987) demonstrated that, in particular, inappropriately low estimates of fractional comminution rates can impair model prediction, although effects remain smaller with highquality diets. Considering the low fibre content and the very high rumen digestibility of the 
diets (91.8 (SD 1.2) \% neutral-detergent fibre (NDF) degradability in sacco and 75.8 (SD 5.4) \% rumen NDF digestion in vivo; Van Vuuren et al. 1992, 1993), the fractional comminution rate was increased from $4.5 / \mathrm{d}$ to $8.5 / \mathrm{d}$. The resulting comminution rate in the model $(8.5 / \mathrm{d} \times 0.333=2.84 / \mathrm{d})$ approaches the highest estimates reported in the literature.

Estimates of the particle size factor are much more difficult to obtain, because it not only represents the proportion of small particles in the diet but also considers the apparent availability properties of particles in the rumen (Baldwin et al. 1987). Because diets consisted largely of fresh perennial ryegrass harvested at an early stage of maturity, a particle size factor of 0.6 was taken instead of 0.4 or 0.5 assumed by Baldwin et al. (1987).

DA model. All model inputs for the DA model could be derived from the experimental data, except for the so-called $G$ parameter that partitions total carbohydrate fermentation into that of soluble carbohydrates, starch, or NDF, and has a value between 0.0 and 1.0 . Danfær (1990) considered $G$ to be dependent on the diet fed and calibrated a value of 0.0006 on a reference diet. Such small values always cause a model response of almost no escape of starch (Danfær, 1990), although in vivo duodenal flow of starch may increase considerably with increasing starch content in the diet (Nocek \& Tamminga, 1991). Danfær (1990) probably encountered no inaccuracies in predicted duodenal flow of starch because his reference diet contained very little starch $(30 \mathrm{~g} / \mathrm{kg})$. Another consequence of such a small $\mathrm{G}$ value is that the model responds with a decreased duodenal flow of rapidly fermentable carbohydrates to an increased content of these carbohydrates in the diet (Danfær, 1990), irrespective of other diet characteristics. These model responses were considered incorrect and $G$ was arbitrarily increased to a high value of 0.4 , which enabled the model to simulate a substantial duodenal flow of starch with increased starch content in a diet.

The DA model does not distinguish between rumen pools of soluble and insoluble substrate. Therefore, it was assumed that the fractional outflow rate of rumen substrates is determined by observed fractional outflow rates of both fluid and OM, as described previously (Danfær, 1990). Because microbes flow out of the rumen with both particles and fluid, the fractional outflow rate of microbial matter was assumed to be half the observed fractional outflow rate of fluid (Danfær, 1990). This assumption allowed for variation in outflow rate of microbial matter with observed values, yet estimates still agreed reasonably with Danfær's original estimate.

DY model. Experimental data delivered all required inputs for the DY model. Observed fractional outflow rates of fluid and OM were used as estimates for the model parameters of fluid and particle outflow respectively.

\section{Model predictions}

Predicted rumen pool sizes and duodenal flows were compared amongst models and evaluated with measured values. The prediction error was calculated as the square root of the mean squared differences between predicted and observed values, expressed as a percentage of the observed mean. Considering the large standard deviation of the experimental data (Van Vuuren et al. 1992, 1993), a $10 \%$ deviation as a criterion for prediction accuracy seems reasonable and predictions were declared accurate at a prediction error $<10 \%$. Other predictions (fermentation of substrate into VFA and incorporation of substrate into microbial matter) could only be compared amongst models, because no experimental data were available. 


\section{RESULTS}

Model responses to changes in input were similar to observed responses for duodenal flows of NAN, AAN, MAAN, MN, starch, NDF, lipids and OM. However, consistent deviations existed amongst models and between predicted and observed values. Duodenal flows of NAN and OM were predicted accurately by all three models (Fig. 1(a)). Rumen pools were most accurately predicted by the BA model, with the smallest prediction errors for NAN, MN, NDF and OM (Fig. 1(b)). Intraruminal transactions and duodenal flows of nutrients will be discussed in the following section.

\section{Rumen transactions of substrates}

Rumen transactions and duodenal flow of organic matter. The models differed in predicted amounts of OM either fermented into VFA or incorporated into microbial mass (Tables 2 and 3). Prediction errors of duodenal flow of OM remained small with every model (Figs. 1(a) and 2), despite their different predictions of the amount of fermented OM (i.e. OM not appearing in the duodenum).

Rumen transactions of carbohydrates. Soluble and degraded carbohydrates are either fermented into VFA, incorporated into microbial mass, or escape from the rumen without being used by micro-organisms. On average, fermentation accounted for 68,57 and $53 \%$, incorporation for 13,20 and $32 \%$, and escape for 19,22 and $15 \%$ of carbohydrate input with the BA, DA and DY models respectively (Table 2). Differences amongst models in predicted amounts of carbohydrate fermented and incorporated partially compensated for each other. The predicted amount of carbohydrate available for microbial use was highest in the DA and DY models because they had the highest sum of degraded insoluble starch and NDF (Table 2). A different order was predicted with the BA and DA models for the amount of carbohydrate actually utilized by microbes as apparent from predicted escape of feed carbohydrates.

Duodenal flows of carbohydrate. The DA and DY models underpredicted the duodenal flow of NDF (Figs. 1(a) and 3(a)). The DA model underpredicted the duodenal flow of starch of the high-starch diet (diet 2), whereas the DY and BA models predicted more accurately, although still deviating from the observed values (Fig. 3(b)). On the other hand, the DA model gave more accurate predictions of duodenal starch flow on total herbage diets (diets 1, 4, 5, 6 and 7), in contrast to over- and underprediction with the BA and DY models respectively. The BA model predicted the largest duodenal flow of starch because of the highest starch content in microbial matter (on average, the microbial fractions in duodenal flow of starch were 210,40 and $110 \mathrm{~g} / \mathrm{kg}$ in the BA, DA and DY models respectively). Predictions of the duodenal flow of soluble carbohydrate could not be evaluated because no experimental data were available. Large duodenal flows predicted by the DA and DY models contrasted with low duodenal flows predicted by the BA model (Fig. 3(c)).

Because the excess duodenal flow of soluble carbohydrate in the DY and DA models (Fig. 3(c)) compensated for the lower duodenal flows of NDF and starch (Table 2), the models predicted a comparable duodenal flow of carbohydrate (on average, 250, 230 and $180 \mathrm{~g} / \mathrm{kg}$ of the rumen input of feed carbohydrate with the BA, DA and DY models respectively).

Rumen transactions and duodenal flow of lipid. The BA model predicted duodenal flow of lipid accurately (Figs. 1(a) and 3(d)). The DA and DY models overpredicted because the assumed lipid content in microbial matter and the lipid utilization by microbes were lower than in the BA model. 

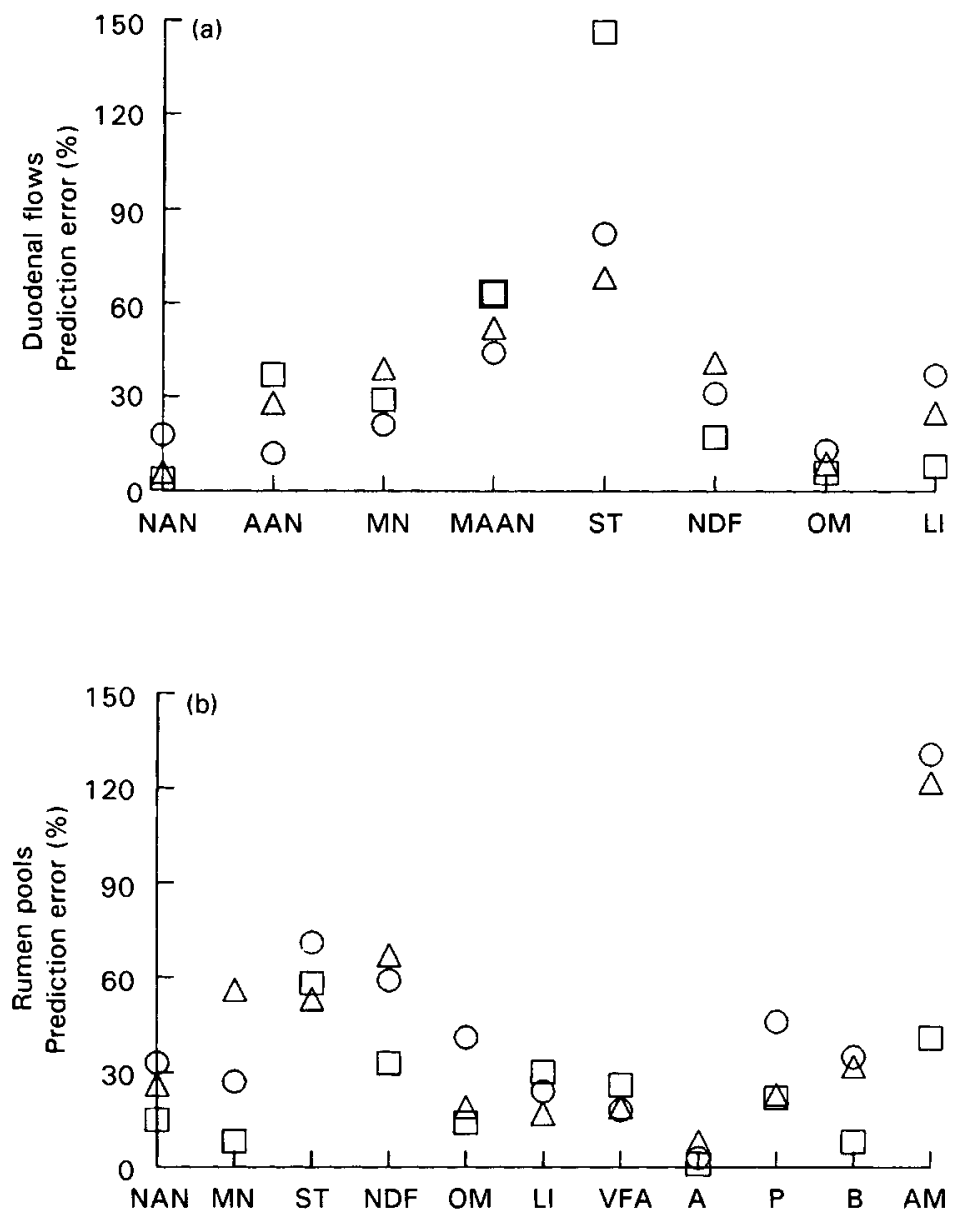

Fig. 1. Prediction errors of (a) duodenal flows and (b) rumen pools on seven test diets by the models of Baldwin (1995; $\square)$, Danfær $(1990 ; O)$ and Dijkstra et al. $(1992 ; \triangle)$. Errors were calculated as square root of mean squared differences between predictions and observations, expressed as a percentage of the observed mean. AAN, amino-acid N; A, molar percentage of acetate; AM, concentration of ammonia; B, molar percentage of butyrate; LI, lipids; MAAN, microbial amino-acid N; MN, microbial N; NAN, non-ammonia N; NDF, neutral-detergent fibre; OM, organic matter; $P$, molar percentage of propionate; ST, starch; VFA, concentration of volatile fatty acids. Prediction errors were calculated from duodenal flows in $\mathrm{g} / \mathrm{d}$ or $\mathrm{g} \mathrm{N} / \mathrm{d}$ or from rumen pools in $\mathrm{g}$ or $\mathrm{g} \mathrm{N}$, except for VFA and AM in mmol/1 and molar percentages of VFA in \%.

Rumen transactions of nitrogen. The DA model predicted the highest degradation of feed AAN. Soluble and degraded AAN is either incorporated into microbial mass, fermented into VFA and $\mathrm{NH}_{3}$ or escapes from the rumen. Differences amongst models in fermented AAN were opposite to differences in incorporated feed AAN (on average there was 64,50 and $56 \%$ fermentation, and 14,35 and $23 \%$ incorporation of the rumen input of feed AAN with the BA, DA and DY models respectively; Table 3). Considerable differences remained amongst models in the predicted escape of feed $\mathrm{N}$ to the duodenum.

Duodenal flows of nitrogen. The BA and DY models predicted the duodenal flow of NAN accurately, whereas the DA model underpredicted (Figs. 1(a) and 4(a)). However, the microbial contribution to duodenal NAN appeared to be overpredicted in all three models (Figs. 1(a) and 4(c)). 
Table 2. Predicted duodenal flows and intraruminal transactions of carbohydrates by the models of Baldwin (1995; BA), Danfor (1990; DA) and Dijkstra et al. (1992; DY) for seven test diets

\begin{tabular}{|c|c|c|c|c|c|c|c|}
\hline Diet... & 1 & 2 & 3 & 4 & 5 & 6 & 7 \\
\hline \multicolumn{8}{|c|}{ Duodenal flows $(\mathrm{g} / \mathrm{d})$} \\
\hline \multicolumn{8}{|c|}{ Feed $\mathrm{CH}_{2} \mathrm{O}^{*}$} \\
\hline BA & 1654 & 3322 & 2223 & 1127 & 1829 & 1021 & 934 \\
\hline DA & 1771 & 2254 & 2317 & 2072 & 2157 & 1577 & 1470 \\
\hline DY & 1435 & 1810 & 1415 & 1074 & 1662 & 1038 & 748 \\
\hline \multicolumn{8}{|c|}{ Microbial starch } \\
\hline BA & 524 & 490 & 551 & 469 & 560 & 420 & 478 \\
\hline DA & 101 & 108 & 101 & 153 & 84 & 93 & 128 \\
\hline DY & 252 & 435 & 363 & 192 & 297 & 193 & 330 \\
\hline \multicolumn{8}{|c|}{ Microbial remains $\dagger$} \\
\hline BA & 295 & 279 & 317 & 266 & 321 & 238 & 270 \\
\hline DA & 914 & 972 & 914 & 1382 & 762 & 845 & 1166 \\
\hline DY & 709 & 660 & 726 & 551 & 706 & 497 & 540 \\
\hline \multicolumn{8}{|c|}{ Transactions (g/d) } \\
\hline \multicolumn{8}{|c|}{ Degraded insoluble $\mathrm{CH}_{2} \mathrm{O}$} \\
\hline $\mathrm{BA}$ & 5116 & 4257 & 4827 & 3918 & 4927 & 4332 & 4195 \\
\hline DA & 5668 & 6574 & 5782 & 3986 & 5516 & 4380 & 4349 \\
\hline DY & 5693 & 6305 & 6042 & 4455 & 5573 & 4529 & 4520 \\
\hline \multicolumn{8}{|c|}{ Fermented $\mathrm{CH}_{2} \mathrm{O}$} \\
\hline BA & 6350 & 5624 & 6769 & 5003 & 6583 & 5324 & 6053 \\
\hline DA & 5950 & 5877 & 6054 & 3329 & 5893 & 4181 & 4795 \\
\hline DY & 4846 & 5216 & 5674 & 3863 & 5058 & 3931 & 4487 \\
\hline \multicolumn{8}{|c|}{ Incorporated $\mathrm{CH}_{2} \mathrm{O}_{+}^{+}$} \\
\hline $\mathrm{BA}$ & 1207 & 1136 & 1315 & 1134 & 1327 & 968 & 1147 \\
\hline DA & 1477 & 1937 & 1926 & 1853 & 1677 & 1544 & 1858 \\
\hline DY & 2930 & 3056 & 3218 & 2327 & 3019 & 2344 & 2899 \\
\hline
\end{tabular}

* $\mathrm{CH}_{2} \mathrm{O}$, total of solubilized carbohydrates, starch and neutral-detergent fibre.

+ Microbial organic matter - microbial $\mathrm{N} \times 6.25$ - microbial starch.

$\ddagger \mathrm{CH}_{2} \mathrm{O}$ input - fermented $\mathrm{CH}_{2} \mathrm{O}$ - duodenal flow of feed $\mathrm{CH}_{2} \mathrm{O}$.

Assuming feed non-AA NAN is input to the rumen $\mathrm{NH}_{3}$ pool, predicted duodenal flows of protein were considered to consist of AAN only. Duodenal flow of NAN minus MN and duodenal flow of AAN minus MAAN provide estimates of feed $\mathrm{N}$ and feed AAN respectively, that escapes from the rumen. Comparison of these calculations on experimental data and model predictions (Table 3) shows that the duodenal flow of nonAA NAN (e.g. nucleic acids) is strongly underpredicted by all models. On average, the BA, DA and DY models predicted 81,57 and $80 \%$ of observed duodenal flow of feed N, 136, 93 and $132 \%$ of feed AAN, and 30, 38 and $65 \%$ of non-AA NAN respectively (prediction errors of feed N 18, 47 and $25 \%$, of feed AAN 38, 24 and $27 \%$, and of non-AA NAN 71, 62 and $36 \%$ with the BA, DA and DY models respectively; Table 3).

\section{Products of microbial substrate utilization}

Fermentation end-products. Because VFA production was not measured, models could only be evaluated on the concentration and molar percentage of VFA. Differences between models in the predicted production of VFA were inverted in the predicted concentrations because of different absorption rates. Although the BA model predicted the largest VFA production, it underpredicted rumen concentration of VFA (Fig. 5(a)) with the largest 
Table 3. Observed (Exp) and predicted duodenal flows and intraruminal transactions of nitrogen fractions by the models of Baldwin (1995; BA), Danfar (1990; DA) and Dijkstra et al. (1992; DY) for seven test diets

\begin{tabular}{|c|c|c|c|c|c|c|c|}
\hline Diet . & 1 & 2 & 3 & 4 & 5 & 6 & 7 \\
\hline \multicolumn{8}{|c|}{ Duodenal flows (g N/d) } \\
\hline \multicolumn{8}{|c|}{ Feed N* } \\
\hline Exp & 154 & 164 & 154 & 87 & 116 & 72 & 85 \\
\hline $\mathrm{BA}$ & 126 & 150 & 125 & 75 & 90 & 54 & 61 \\
\hline DA & 61 & 66 & 60 & 67 & 76 & 51 & 58 \\
\hline DY & 92 & 128 & 95 & 94 & 92 & 63 & 73 \\
\hline \multicolumn{8}{|c|}{ Microbial N } \\
\hline $\operatorname{Exp}$ & 255 & 260 & 242 & 220 & 255 & 190 & 224 \\
\hline $\mathrm{BA}$ & 264 & 247 & 277 & 236 & 282 & 212 & 240 \\
\hline $\mathrm{DA}$ & 271 & 274 & 278 & 158 & 274 & 179 & 201 \\
\hline DY & 315 & 295 & 323 & 247 & 315 & 222 & 242 \\
\hline \multicolumn{8}{|c|}{ Feed AAN* } \\
\hline Exp & 80 & 97 & 78 & 55 & 90 & 36 & 68 \\
\hline BA & 127 & 150 & 123 & 76 & 91 & 55 & 60 \\
\hline $\mathrm{DA}$ & 61 & 67 & 60 & 67 & 75 & 51 & 58 \\
\hline DY & 92 & 129 & 94 & 94 & 92 & 63 & 74 \\
\hline \multicolumn{8}{|c|}{ Microbial AAN } \\
\hline Exp & 172 & 176 & 163 & 152 & 171 & 124 & 156 \\
\hline $\mathrm{BA}^{\mathrm{T}}$ & 226 & 212 & 238 & 202 & 242 & 181 & 206 \\
\hline DA & 217 & 219 & 223 & 127 & 220 & 143 & 162 \\
\hline DY & 227 & 212 & 233 & 178 & 227 & 160 & 174 \\
\hline \multicolumn{8}{|c|}{ Non-AAN NAN } \\
\hline Exp & 157 & 151 & 155 & 100 & 110 & 102 & 85 \\
\hline $\mathrm{BA}$ & 37 & 35 & 41 & 33 & 39 & 30 & 35 \\
\hline $\mathrm{DA}$ & 54 & 54 & 55 & 31 & 55 & 36 & 39 \\
\hline DY & 88 & 82 & 91 & 69 & 88 & 62 & 67 \\
\hline \multicolumn{8}{|c|}{ Transactions ( $\mathrm{g} \mathrm{N} / \mathrm{d}$ ) } \\
\hline \multicolumn{8}{|c|}{ Degraded AAN } \\
\hline BA & 253 & 156 & 198 & 152 & 173 & 168 & 204 \\
\hline DA & 414 & 372 & 371 & 357 & 374 & 299 & 410 \\
\hline DY & 337 & 244 & 271 & 196 & 222 & 187 & 232 \\
\hline \multicolumn{8}{|c|}{ Fermented AAN } \\
\hline BA & 267 & 202 & 215 & 272 & 268 & 230 & 331 \\
\hline $\mathrm{DA}$ & 183 & 191 & 190 & 198 & 193 & 185 & 245 \\
\hline DY & 248 & 184 & 204 & 214 & 221 & 203 & 304 \\
\hline \multicolumn{8}{|c|}{ Incorporated AAN $\dagger$} \\
\hline BA & 60 & 64 & 70 & 51 & 67 & 42 & 38 \\
\hline $\mathrm{DA}$ & 204 & 153 & 152 & 129 & 152 & 86 & 124 \\
\hline DY & 114 & 107 & 110 & 91 & 112 & 60 & 52 \\
\hline \multicolumn{8}{|c|}{ Net $\mathrm{MN}$ synthesis from $\mathrm{NH}_{3} \ddagger$} \\
\hline BA & 204 & 183 & 207 & 185 & 215 & 170 & 202 \\
\hline DA & 67 & 121 & 126 & 29 & 122 & 93 & 77 \\
\hline DY & 201 & 188 & 213 & 156 & 203 & 162 & 190 \\
\hline
\end{tabular}

AAN, amino acid N; MN, microbial N; NAN, non-ammonia $\mathbf{N}$.

* Feed AAN $=$ total AAN - microbial AAN; feed $N=N A N-$ microbial $N$.

$\dagger$ Input AAN - duodenal flow of feed AAN - fermented AAN.

‡ Duodenal flow of MN - incorporated AAN. 


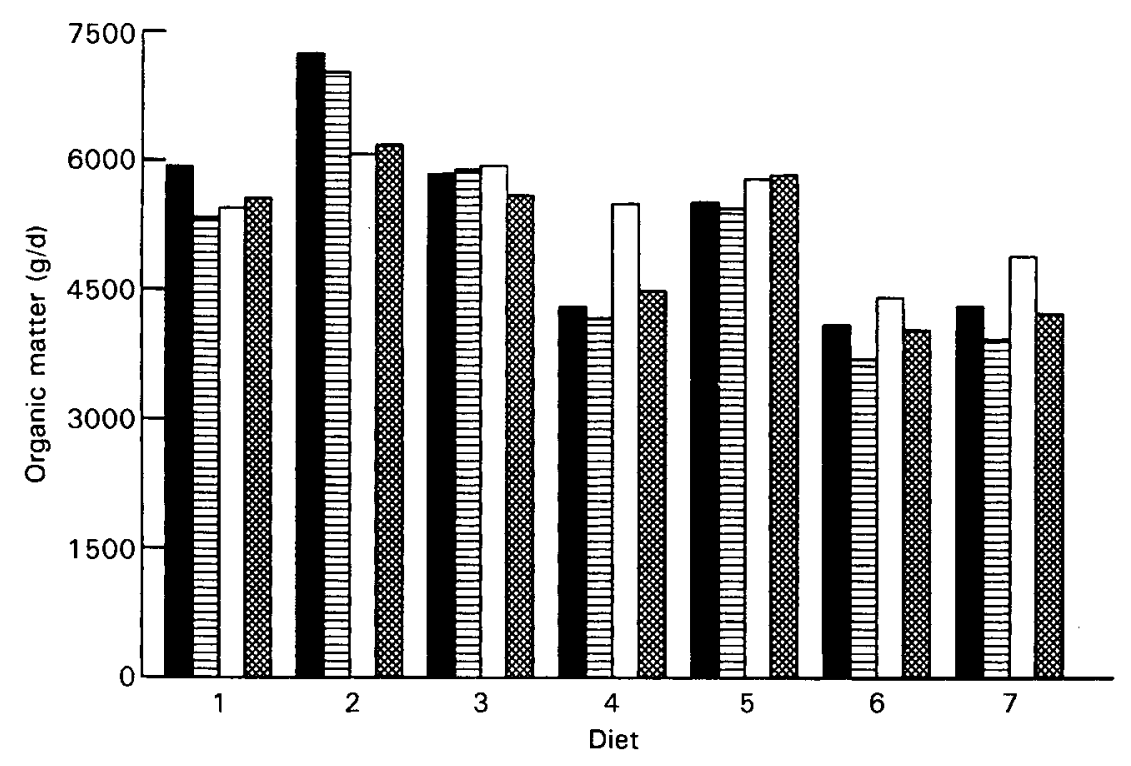

Fig. 2. Comparison of observed ( $\square$ ) and predicted values of duodenal flow of organic matter on seven test diets by the models of Baldwin (1995; 首 ), Danfær (1990; $\square$ ) and Dijkstra et al. (1992; $)$.

prediction error (Fig. 1(b)). Model predictions of the molar percentage of individual VFA deviated strongly from the observed percentages (Figs. 1(b) and 6(a, b and c)). Only the DY model includes the formation of valerate (overpredicted with a prediction error of $515 \%$, results not shown). This extra VFA influences VFA predictions, because attribution of the $\mathrm{C}$ in valerate to acetate, propionate, or butyrate would increase the VFA production and alter the molar percentages. $\mathrm{NH}_{3}$ is an end-product of protein fermentation in addition to VFA and predicted and observed rumen concentrations of $\mathrm{NH}_{3}$ differed strongly (Figs. 1(b) and 5(b)). In particular the response of the BA and DY models (except on diet 7 with the DY model) to input variation corresponded to the observed response in concentration of $\mathrm{NH}_{3}$.

Microbial synthesis. The observed duodenal flows of MN and MAAN on diets 4-7 were much lower with the AA profile method than with the DAPA method (Fig. 4, (c) and (d)). Because results with the DAPA method were considered to be more accurate, for reasons that will be discussed, model predictions were evaluated only on observations with the DAPA method.

The models predicted similar duodenal flows of $\mathrm{MN}$ (Fig. 4, (c) and (d)). Consequently, differences amongst models in the predicted incorporation of AAN (26, 77 and $45 \%$ of duodenal flow of MN with the BA, DA and DY models respectively) compensated with opposite differences in net $\mathrm{MN}$ synthesis from $\mathrm{NH}_{3}(78,36$ and $58 \%$ of duodenal flow of $\mathrm{MN}$ respectively). In contrast to the DY model, the assumed AAN content in MN seemed to be too high in the BA and DA models because duodenal flow of MAAN was more overpredicted than that of $\mathrm{MN}$ (Fig. 4, (c) and (d)). Further, absolute overpredictions of the duodenal flow of MAAN and AAN were of a similar size in the BA and DY models (Fig. 4, (b) and (d)). This is illustrated by average prediction errors of the duodenal flow of MAAN $v$. AAN in the BA, DA and DY models of $40 v .37,27 v .12$, and 31 v. $28 \%$ respectively (Fig. 1(a)). 

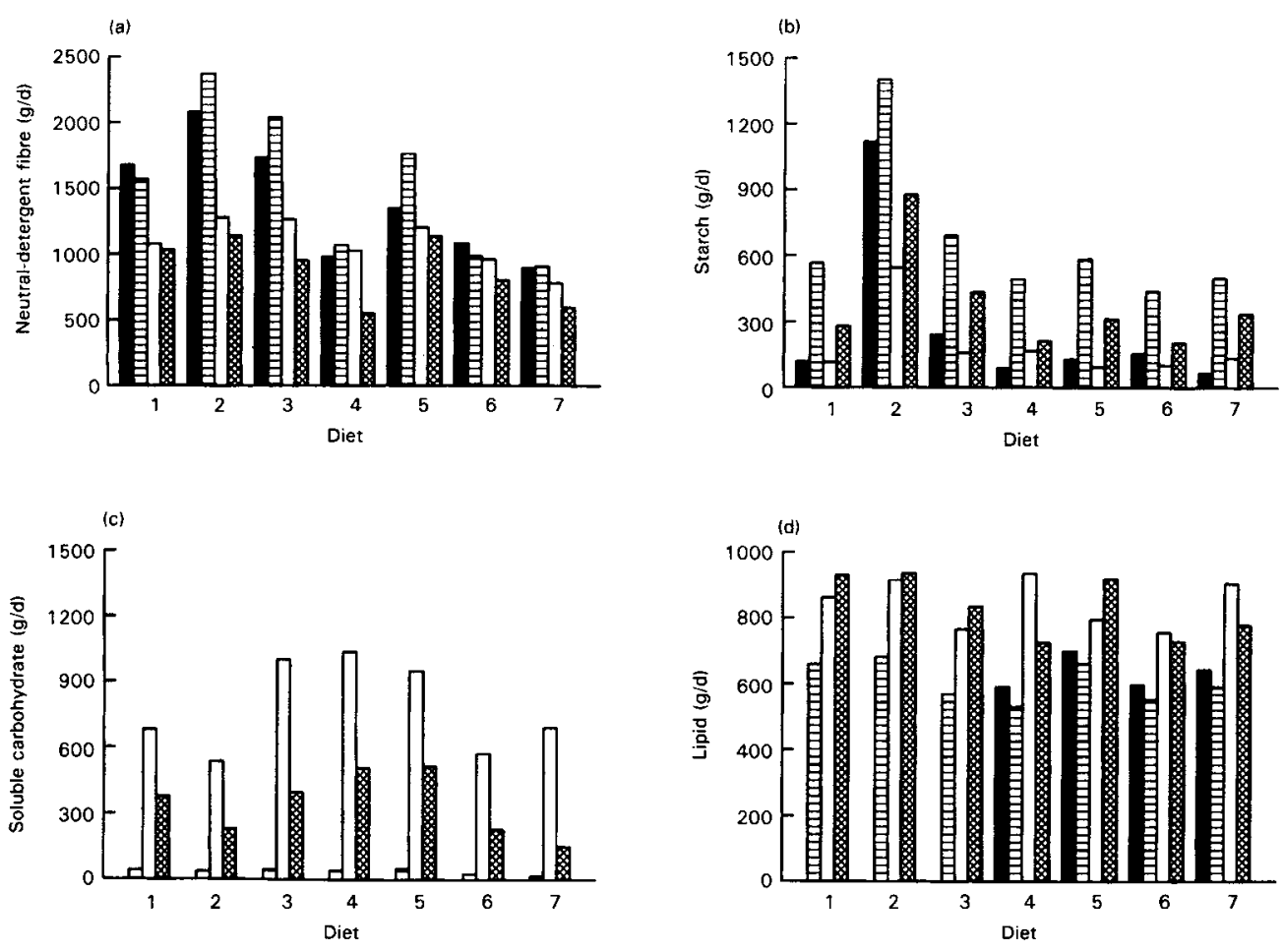

Fig. 3. Comparison of observed ( $\square$ ) and predicted values of the duodenal flow of (a) neutral-detergent fibre, (b) starch, including solubilized starch, (c) soluble carbohydrate including solubilized NDF and excluding solubilized starch and (d) lipids on seven test diets by the models of Baldwin (1995; 目), Danfær (1990; $\square)$ and Dijkstra et al. (1992; $)$.

\section{DISCUSSION}

\section{Input parameters}

The necessity to estimate some unknown parameter inputs in the present study is inherent to the use of these rumen models and should not be considered as model adjustment. The model-builders clearly stated that these parameters are not internal model parameters but required inputs to the model that are diet-specific and need to be estimated (Baldwin et al. 1987; Danfær, 1990; Dijkstra et al. 1992). The builders also had to estimate appropriate values for lack of experimental data, although it was not always described how those parameters were estimated or should be estimated (Baldwin et al. 1987; Danfær, 1990). For example, if originally published values were used for the particle comminution rate and the particle size factor in the BA model, a duodenal flow of NDF of $3.2 \mathrm{~kg} / \mathrm{d}$ was predicted for diet 1 instead of $1.7 \mathrm{~kg} / \mathrm{d}$ as observed. This unrealistic result would affect the behaviour of the BA model so much that a comparison amongst the models would become irrelevant. In the present study, appropriate parameter inputs were estimated. Nevertheless, it should be realized that the method of estimation might not correspond to the method the modelbuilders used. In particular, estimation of rumen particle dynamics is critical and complicates the interpretation of evaluation results.

Choosing parameter values that seem more appropriate than the published estimates caused the BA model to predict duodenal flow of NDF more accurately than the other 

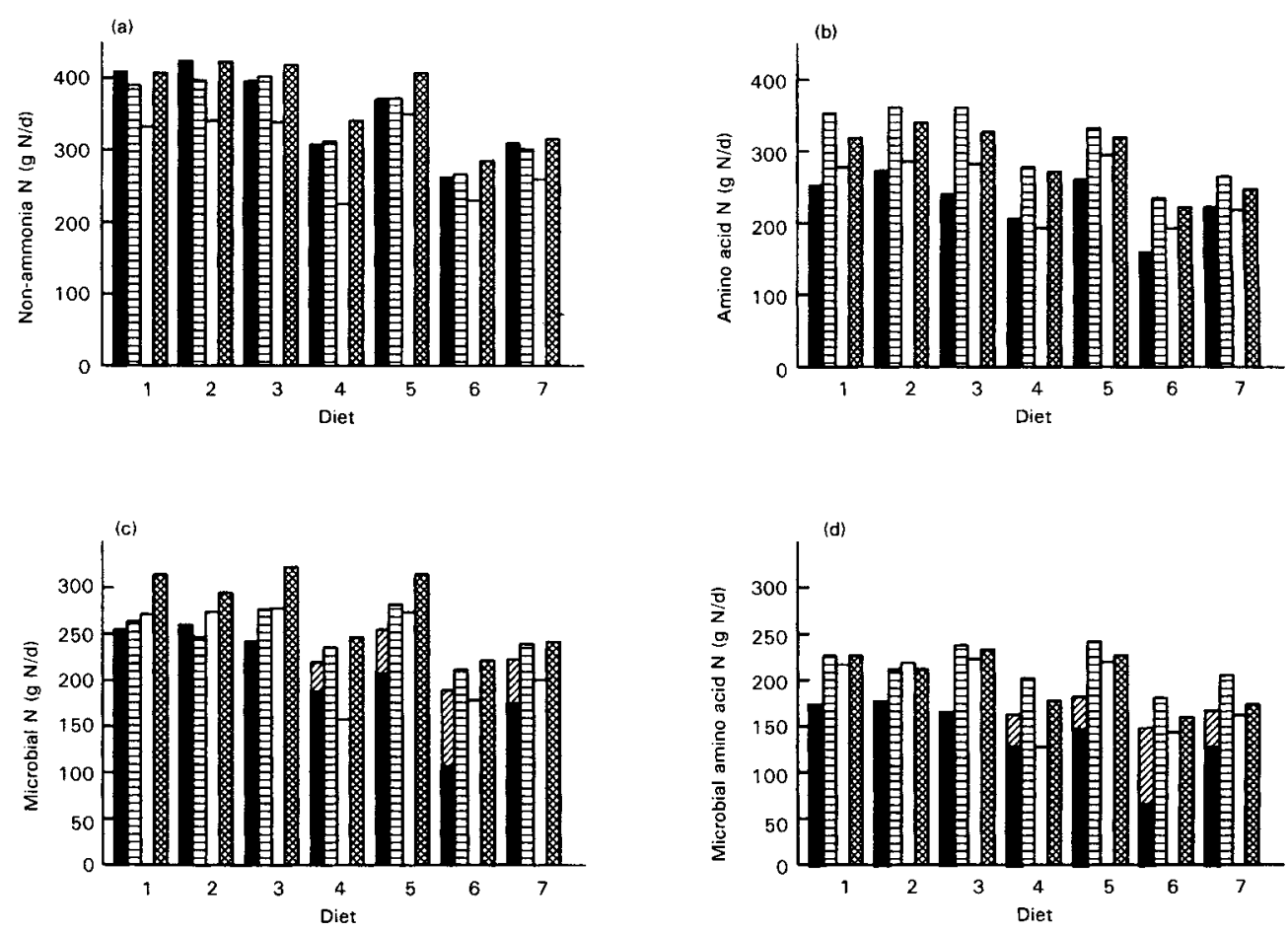

Fig. 4. Comparison of observed ( $\mathbf{a}$ ) and predicted values of the duodenal flow of (a) non-ammonia N, (b) amino acid N, (c) microbial $\mathrm{N}$ and (d) microbial amino acid $\mathrm{N}$ on seven test diets by the models of Baldwin (1995; 自), Danfær (1990;

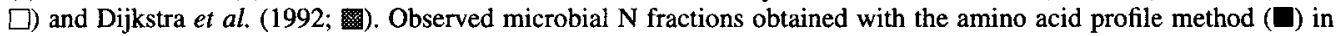
diets 4-7 and with the diaminopimelic acid (DAPA) method (ஐ) in diets 1-7.

models. However, other parameter estimates for rumen outflow might have improved NDF prediction in the DA and DY models also.

Neal et al. (1992) extensively evaluated the DY model and established, in contrast to the results of the present study, accurate predictions of duodenal flow of NDF. This contradiction might be explained by erroneous measurements of duodenal flow of NDF due to sampling errors and sample preparation. However, Van Vuuren et al. (1992) reasoned that these errors caused underestimation rather than overestimation of duodenal flows of NDF. Another possible explanation for the underprediction of duodenal NDF flow with the DY model might be a poor model performance with fractional outflow rates of $\mathrm{OM}$ as parameter input. The DY model was calibrated on an experiment in which Yb was used as a marker for particulate outflow that preferentially binds to small particles, whereas the total content of $\mathrm{OM}$ in the rumen as a marker includes large particles, small particles and soluble OM in rumen fluid. If the soluble fraction in rumen OM outflow is small compared with the particulate fraction (all NDF considered particulate matter and on roughage diets the majority of micro-organisms attached to particles), then the fractional outflow rate of total rumen OM pool is lower than that of the small particle pool. Thus, use of observed fractional outflow rates of rumen OM content in the present study might have resulted in an underestimated fractional outflow rate of small particles, an overpredicted retention and degradation of NDF in the rumen, and consequently an underpredicted duodenal flow of NDF. In the DA model, predicted duodenal flow of NDF can additionally be manipulated 


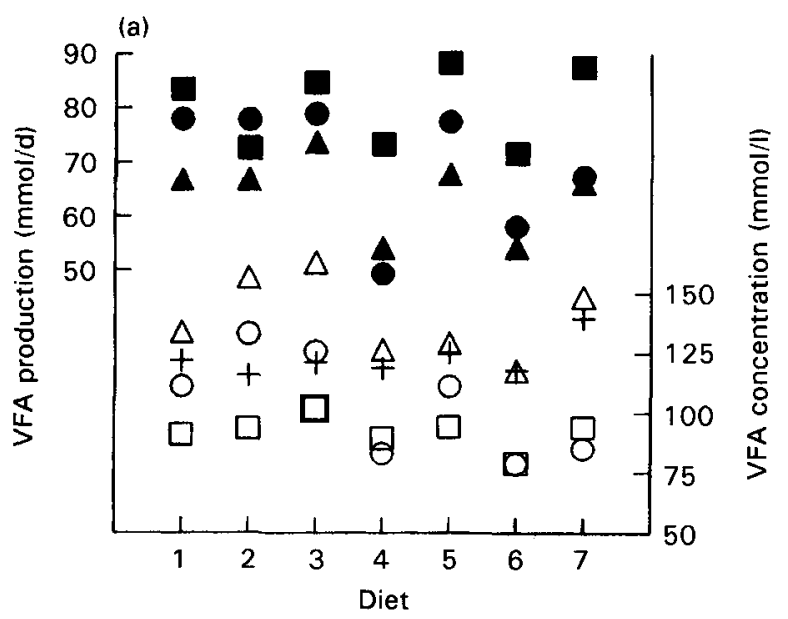

(b)

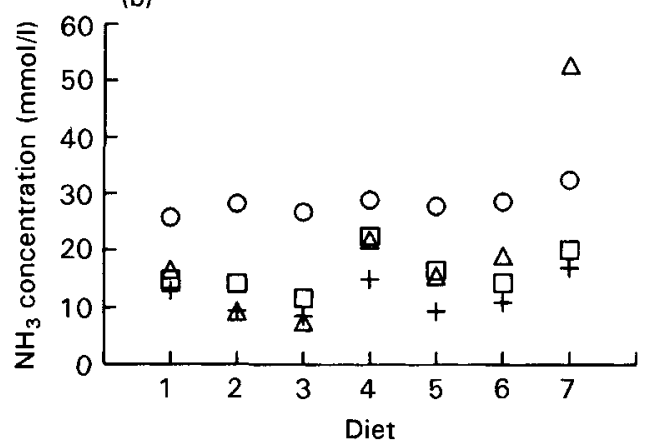

Fig. 5. Comparison of observed (+) and predicted values of (a) volatile fatty acid (VFA) production $(\boldsymbol{\square}, \mathbf{O}, \mathbf{\Delta})$ and concentration $(\square, O, \triangle)$ and (b) ammonia concentration on seven test diets by the models of Baldwin (1995; $\square$ ), Danfær $(1990 ; O)$ and Dijkstra et al. $(1992 ; \triangle)$.

by changing the value of the $\mathrm{G}$ parameter, but the same kind of argument might apply to this model. To conclude this section, the models identify areas of physical and chemical feed description necessary to represent specific relationships occurring in the rumen, but the present study indicates that these areas are still inadequately defined.

\section{Nutrient flows}

Large differences were established in the predicted transactions of carbohydrates and $\mathrm{N}$ in the rumen and in the resulting profile of nutrients that flow from the rumen to the duodenum (Tables 2 and 3; Figs. 3 and 4). However, these results are susceptible to assumptions on the model inputs (already discussed for parameters in the previous section) and measurement errors in the experimental data used.

With the assumption that all feed non-AA NAN is immediately hydrolysed and constitutes an input to the rumen $\mathrm{NH}_{3}$ pool, the predicted duodenal flow of non-AA NAN is assumed to be entirely of microbial origin and escaped feed $\mathrm{N}$ to be $100 \%$ AAN. 
(a)

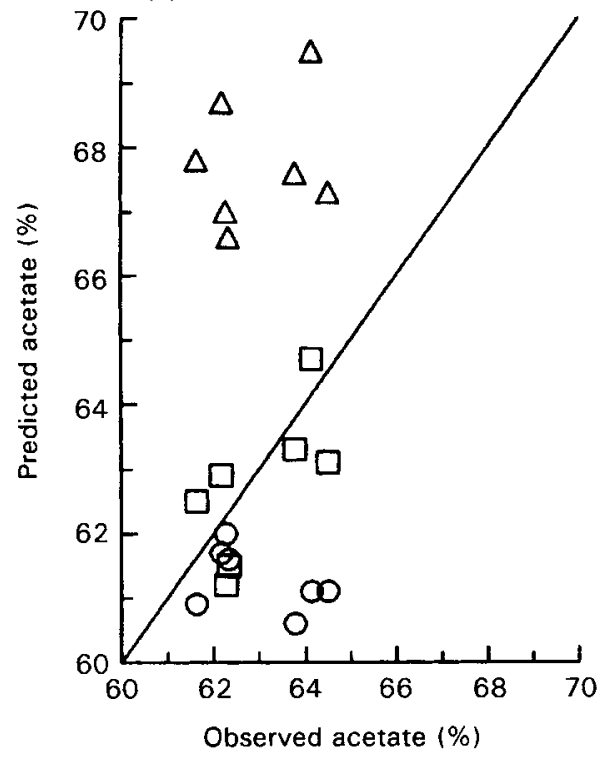

(b)

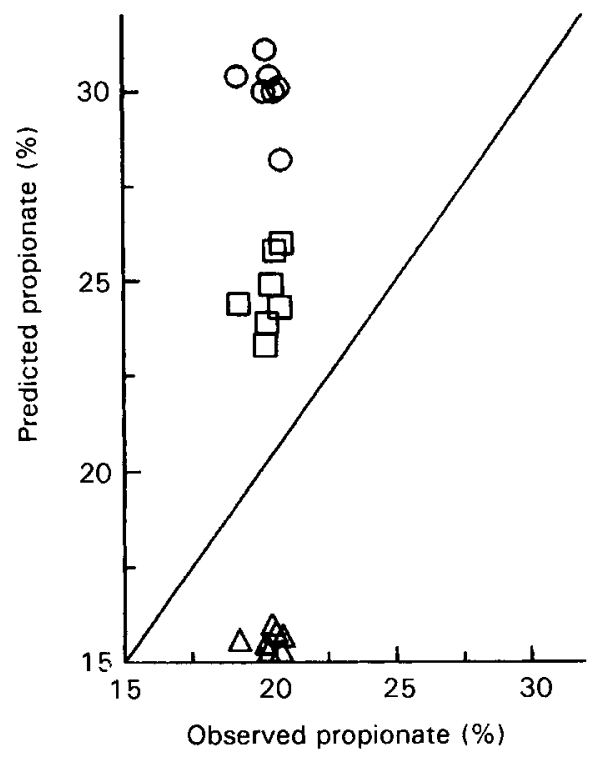

(c)

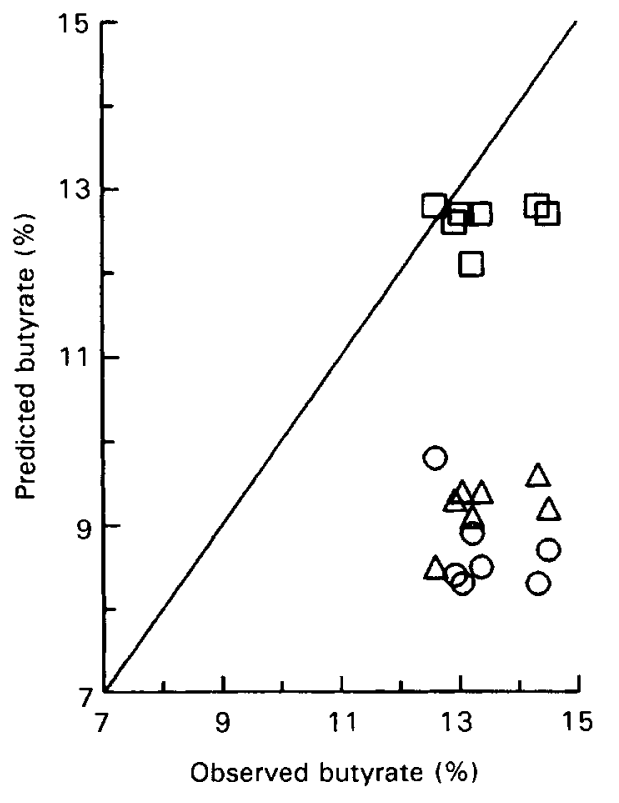

Fig. 6. Comparison of observed and predicted values of (a) molar percentage of acetate, (b) molar percentage of propionate and (c) molar percentage of butyrate on seven test diets by the models of Baldwin (1995; $\square$ ), Danfær (1990; $O)$ and Dijkstra et al. $(1992 ; \triangle)$. In the model of Dijkstra et al. (1992), the sum of predictions is less than $100 \%$ because of additional valerate prediction. 
However, the observed duodenal flows of non-AA NAN were much higher than the predicted values (Table 3), suggesting that some feed non-AA NAN did escape from the rumen. Considering rumen protein as crude protein $(\mathrm{g} \mathrm{N} \times 6.25)$ instead of true protein (no $\mathrm{NH}_{3}$ input from soluble $\mathrm{N}$ ) will reduce predicted error of the duodenal flow of AAN and non-AA NAN. However, caution is necessary with explaining inaccurate prediction from the model representations because also the experimental estimates may be seriously biased.

Of all the measured duodenal flows, that of microbial matter probably has the largest standard deviation and is the least reliable. Therefore, not only the accuracy of model predictions but also the reliability of observed $\mathrm{MN}$ in particular should be evaluated. With the AA profile method, estimates of MAAN or MN were clearly lower with the AA profile method than with the DAPA method (Fig. 4, (c) and (d)). The percentage $\mathrm{N}$ of microbial origin was used to estimate the duodenal flow of MAAN and MN from the observed duodenal flow of AAN and NAN respectively, which seems to be valid at least on diets 4-7 because it resulted in ratios of duodenal flow of MAAN and MN that were comparable with that of the independently observed amounts of AAN and total $N$ found in microbial matter isolated from duodenal samples (68\% AAN). Variability of prediction errors was larger with the AA profile method and estimates of duodenal flow of MN and MAAN on diet 6 are so low that they are highly unlikely. The larger deviations between the predicted and observed duodenal flows of MN and MAAN with the AA profile method does not agree with the uniform prediction error of the duodenal flow of NAN or AAN for all diets (Fig. 4, (a) and (b)). From these arguments it may be concluded that the AA profile method in particular resulted in severely biased and inconsistent estimates of microbial mass in samples of the duodenal contents. In a direct comparison of alternative methods for the quantification of microbial matter, Siddons et al. (1982) also established much higher estimates of microbial $\mathrm{N}$ in rumen digesta of sheep with the DAPA method compared with the AA profile method. In contrast, Voigt et al. (1991) established low but comparable estimates with the AA profile and DAPA method in duodenal digesta of dairy cows. Thus, highly variable results have been obtained with different methods as well as within a single method of microbial quantification.

Further, protozoa were excluded with the isolation of microbial matter from digesta samples and also the DAPA method largely excludes protozoa (Broderick \& Merchen, 1992). Thus, the presence of substantial amounts of protozoal $\mathrm{N}$ in duodenal MN might result in an underestimated experimental value of $\mathrm{MN}$ and consequently an overestimated duodenal flow of feed $\mathrm{N}$, feed AAN and non-AAN NAN. A more substantial contribution of protozoal $\mathrm{N}$ could be expected with diets 2 and 3 containing $330 \mathrm{~g}$ concentrates $/ \mathrm{kg}$ DM intake (Dijkstra, 1994); however, there is no indication of a larger prediction error of $\mathrm{MN}$ flow (Fig. 4(c)). An indication of an underestimated duodenal MN flow might be the much higher duodenal flows of non-AA NAN than can be explained by the outflow of microbial non-AA NAN (Table 3). In conclusion, there is a strong possibility of large bias in the experimental estimates of duodenal flow of MN and MAAN which seriously limits their use for model evaluation.

The models predicted different amounts of fermented substrate (Tables 2 and 3), accompanied by different VFA productions (Fig. 5(a)). For predicting nutrient flows, the production of individual VFA is of particular interest because they are the largest energy fraction absorbed from the gastrointestinal tract (Reynolds et al. 1994). However, no such observations were made in the experiments used. The only VFA observations available were those of concentrations in rumen fluid. The DY model uses the estimated VFA coefficients from Murphy et al. (1982) which describe the stoichiometry of the production 
of acetic, propionic, butyric and valeric acids with fermentation of soluble carbohydrate, starch, hemicellulose, cellulose and protein. These coefficient values resulted in a consistent underprediction of the molar percentages of acetic and butyric acids, and overprediction of those of propionic and valeric acids in rumen fluid. The BA model also uses these coefficient estimates, but with $1.0 \mathrm{~mol}$ propionic acid and $0.5 \mathrm{~mol}$ butyric acid substituted for $1.0 \mathrm{~mol}$ valeric acid. Further, coefficient estimates for protein fermentation were altered and VFA coefficients with fermentation of soluble carbohydrate and starch were made dependent on rumen $\mathrm{pH}$ (Argyle \& Baldwin, 1988). These updated coefficient estimates resulted in the most accurate predictions of the molar percentages of individual VFA in rumen fluid. Earlier coefficient estimates of Baldwin et al. (1970) were applied in the DA model and resulted in the worst predictions. The different VFA absorption kinetics in the BA, DA and DY models will have contributed to these different results. The deviations found between predicted and observed molar percentages of individual VFA in rumen fluid are to be explained by incorrect prediction of the amount of fermented substrate, by incorrect coefficient values, or by incorrect absorption kinetics. Yet, it is uncertain to what extent these deviations may be considered representative of rumen VFA production.

Differences amongst models in the assumed microbial composition and substrate requirements for microbial synthesis can partially originate from the assumption in the BA and DA models that microbes incorporate rumen lipid, whereas the DY model ignores this. Besides the synthesis of the protein fraction in microbial mass, that of the lipid fraction might require the highest amount of substrate for generation of ATP or for incorporation into microbial mass (Czerkawski, 1986; Dijkstra et al. 1992; Baldwin, 1995). The assumptions made in the BA, DA and DY models on the utilization of feed lipid will have influenced the parametrizations adopted for substrate requirement with microbial synthesis. Notwithstanding the small lipid content of the diets in the present study (31 to $41 \mathrm{~g}$ lipid/kg DM intake; Van Vuuren et al. 1992, 1993), such considerations are necessary to explain the higher carbohydrate incorporation in the DY model. Thus, different predictions of the amounts of carbohydrate, $\mathrm{AAN}$ and $\mathrm{NH}_{3}$ that are incorporated and fermented with microbial synthesis must be explained from a different origin of the microbiological data used with model construction or from different assumptions on rumen conditions for microbial growth (Russell, 1984; Van Gylswyk \& Schwartz, 1984; Czerkawski, 1986). To conclude this section on predicted nutrient flows, considerable differences exist in the predicted rumen transactions of carbohydrates and $N$. Although the differences between the BA, DA and DY models largely compensated for each other and resulted in more-or-less comparable predictions of the duodenal flows of OM, total carbohydrate, NAN and MN, large differences were established in the prediction of rumen transactions, duodenal flows of the individual carbohydrate and $\mathrm{N}$ fractions, and production rates of individual VFA.

\section{Implications for future research}

None of the models appeared to be clearly superior in predicting the nutrient flows to the duodenum. Calibration of the BA, DA and DY models apparently made them all predict the generally observed duodenal flows of OM, NAN and MN reasonably well. These comparable predictions result from a compensation of large and systematic differences that occurred in the simulated intraruminal flows. Forcing similar entry rates of soluble 
substrates into rumen fluid (according to the model descriptions the only substrate that can be utilized by micro-organisms) in the BA, DA and DY models was demonstrated to result in comparable differences in microbial metabolism to those found in the present study (Bannink \& de Visser, 1995). Therefore, next to a different formulation of substrate availability, a different formulation of the microbial metabolism seems to cause the model differences established. Broadening the range of experimental conditions concerning amounts of feed intake, roughage: concentrate ratios, $\mathrm{N}$ content in feed, and types of roughage and concentrate will probably result in more distinct model behaviour (Dijkstra $e t$ al. 1992; Neal et al. 1992) and enable a more thorough evaluation of the models.

One aspect of rumen modelling that requires further research is resolving the representation of the microbial metabolism. The models tested differ strongly in concepts and theories applied because of the different objectives they were built with. The validity of these representations could not be tested with the observations used in the present study, although they appear to be the main distinction between the BA, DA and DY models and were shown to result in differing profiles of nutrient flows. More precise and detailed measurement of microbial and non-utilized feed fractions in carbohydrate, nitrogenous and other constituents in duodenal OM, might identify which representation of microbial metabolism is able to describe the transactions of substrates in the rumen. In this respect, the representation of microbial metabolism also needs to address the variation in the composition of microbial matter with changing dietary conditions (Danfær, 1990; Dijkstra et al. 1992). Further, most ingested OM is fermented into VFA, but VFA production cannot be evaluated with observations of rumen concentrations. Rumen concentration of $\mathrm{NH}_{3}$ additionally concerns $\mathrm{MN}$ synthesis from $\mathrm{NH}_{3}$ and recycling of $\mathrm{NH}_{3}$ to the rumen. The inconsistency between models in the present study indicates that further research is needed to represent these processes appropriately in rumen models.

Another aspect of rumen modelling that needs further consideration is the representation of particle dynamics and the interactions between particles, substrates and micro-organisms. Evaluation of the dynamic, instead of the steady-state, behaviour of the model might give further insight into the validity of concepts and theories used. Discrete meals administered in feeding trials cause large daily fluctuations of rumen contents and of nutrient flows from the rumen in vivo (Reynolds et al. 1994). Despite the dynamic nature of the models, constant inputs are used with evaluations of simulated steady-state, whereas evaluations of dynamic simulations (Baldwin et al. 1987; Danfær, 1990) have not yet been published (De Peters \& Morris, 1984). Prediction of the daily fluctuation in rumen contents and duodenal flows will probably require inclusion of mechanisms that describe rumen particle dynamics and particle outflow (Sauvant \& Ramangasoavina, 1991; Dijkstra et al. 1992) in particular. However, introduction of more complex mechanisms in extant models might exacerbate a current weakness that is identified in this study: ambiguous or nonidentifiable parameter inputs whose estimation can easily deviate from the method intended by the model-builders. For example, the BA model already includes particle kinetics described with a particle comminution rate and particle size factor. These parameter inputs might be estimated from observations of particle sizes of rumen contents, however, the meaning of these parameters also includes the more complex properties of substrate availability for microbial use which cannot be quantified easily (Baldwin et al. 1987). The DA model has a further weakness in that it is not clear how to estimate the $G$ parameter. If parameter inputs represent concepts that relate more closely to common rumen observations, models will become more easily falsified and model evaluation will give more decisive answers about the validity of the representations chosen. 
In conclusion, this study identified large differences in the underlying mechanisms of microbial metabolism which were related to the different predictions of the profile of nutrient flows from the rumen. Extensive evaluations and comparisons on the same experimental data such as this work may challenge specific representations and enhance understanding of their consequences for predicted nutrient flows. It advances research into rumen function by illustrating the importance of understanding the mechanism of rumen microbial metabolism for accurate prediction of the individual nutrient flows from the rumen.

The authors are very grateful to R. L. Baldwin, A. Danfær and J. Dijkstra for providing model listings.

\section{REFERENCES}

Argyle, J. L. \& Baldwin, R. L. (1988). Modeling of the rumen water kinetics and effects on rumen pH changes. Journal of Dairy Science 71, 1178-1188.

Baldwin, R. L. (1995). Modelling Ruminant Digestion and Metabolism. London: Chapman \& Hall.

Baldwin, R. L., Lucas, H. L. \& Cabrera, R. (1970). Energetic relationships in the formation and utilization of fermentation end-products. In Physiology of Digestion and Metabolism in the Ruminant, pp. 319-334 [A. T. Phillipson, E. F. Annison, D. G. Amstrong, C. C. Balch, R. S. Cromline, R. S. Hardy, P. N. Hobson, and R. D. Keynes, editors]. Newcastle upon Tyne: Oriel Press.

Baldwin, R. L., Thornley, J. H. M. \& Beever, D. E. (1987). Metabolism of the lactating cow. II. Digestive elements of a mechanistic model. Journal of Dairy Research 54, 107-131.

Bannink, A. \& de Visser, H. (1995). Comparison of mechanistic rumen models on microbial metabolism. In Methods in Modelling Herbivore Nutrition. Satellite of IVth International Symposium on the Nutrition of Herbivores [D. Sauvant, editor]. Paris, France: Institut National Agronomique Paris-Grignon and Institut National de la Recherche Agronomique.

Bosch, M. W. (1991). Influence of Stage of Maturity of Grass Silages on Digestion Processes in Dairy Cows. $\mathrm{PhD}$ Thesis, Wageningen Agricultural University, The Netherlands.

Broderick, G. A. \& Merchen, N. R. (1992). Markers for quantifying microbial protein synthesis in the rumen. Journal of Dairy Science 75, 2618-2632.

Czerkawski, J. W. (1986). An Introduction to Rumen Studies. Oxford: Pergamon Press.

Danfær, A. (1990). A Dynamic Model of Nutrient Digestion and Metabolism in Lactating Dairy Cows. PhD Thesis, Report 671, National Institute of Animal Science, Denmark.

De Peters, E. J. \& Morris, J. G. (1984). Discussion: rumen digestion and digestion end products. In Modeling Ruminant Digestion and Metabolism. Proceedings of the Second International Workshop, pp. 63-68 [R. L. Baldwin and A. C. Bywater, editors]. Davis, California: University of California.

Dijkstra, J. (1994). Simulation of the dynamics of protozoa in the rumen. British Journal of Nutrition 72, 679699.

Dijkstra, J., Neal, H. D. St C., Beever, D. E. \& France, J. (1992). Simulation of nutrient digestion, absorption and outflow in the rumen: model description. Journal of Nutrition 122, 2239-2256.

Goswami, A. K. \& Willcox, J. S. (1969). Effect of applying increasing levels of nitrogen to ryegrass. I. Composition of various nitrogenous fractions and free amino acids. Journal of the Science of Food and Agriculture 20, 592-595.

McLeod, M. N. \& Minson, D. J. (1988). Large particle breakdown by cattle eating ryegrass and alfalfa. Journal of Animal Science 66, 992-999.

Murphy, M. R., Baldwin, R. L. \& Koong, L. J. (1982). Estimation of stoichiometric parameters for rumen fermentation of roughage and concentrate diets. Journal of Animal Science 55, 411-421.

Neal, H. D. St C., Dijkstra, J. \& Gill, M. (1992). Simulation of nutrient digestion, absorption and outflow in the rumen: model evaluation. Journal of Nutrition 122, 2257-2272.

Nocek, J. E. \& Tamminga, S. (1991). Site of digestion of starch in the gastrointestinal tract of dairy cows and its effect on milk yield and composition. Journal of Dairy Science 74, 3598-3629.

Poppi, D. P., Minson, D. J. \& Ternouth, J. H. (1981). Studies of cattle and sheep eating leaf and stem fractions of grasses. III. The retention time in the rumen of large feed particles. Australian Journal of Agricultural Research 32, 123-137.

Reynolds, C. K., Harmon, D. L. \& Cecava, M. J. (1994). Absorption and delivery of nutrients for milk protein synthesis by portal-drained viscera. Joumal of Dairy Science 77, 2787-2808. 
Russell, J. B. (1984). Factors influencing competition and composition of the rumen bacterial flora. In Proceedings of the International Symposium on Herbivore Nutrition in the Subtropics and Tropics, pp. 313345 [F. C. M. Gilchrist and R. I. Mackie, editors]. Craighall: The Science Press.

Sauvant, D. \& Ramangasoavina, B. (1991). Rumen modelling. In Rumen Microbial Metabolism and Ruminant Digestion, pp. 283-296 [J.-P. Jouany, editor]. Paris, France: Institut National de la Recherche Agronomique.

Siddons, R. C., Beever, D. E. \& Nolan, J. V. (1982). Comparison of methods for the estimation of microbial nitrogen in duodenal digesta of sheep. British Journal of Nutrition 48, 377-389.

Speckhart, F. H. \& Green, W. L. (1976). A Guide to Using CSMP - the Continuous System Modeling Program. New Jersey: Prentice-Hall.

Van Gylswyk, N. O. \& Schwartz, H. M. (1984). Microbial ecology of the rumen of animals fed high-fibre diets. In Proceedings of the International Symposium on Herbivore Nutrition in the Subtropics and Tropics, pp. 359-377 [F. C. M. Gilchrist and R. I. Mackie, editors]. Craighall: The Science Press.

Van Vuuren, A. M., Krol-Kramer, F., van der Lee, R. A. \& Corbijn, H. (1992). Protein digestion and intestinal amino acids in dairy cows fed fresh Lolium perenne with different nitrogen contents. Journal of Dairy Science 75, 2215-2225.

Van Vuuren, A. M., van der Koelen, C. J. \& Vroons-de Bruin, J. (1993). Effects of partial replacement of ryegrass by concentrates high in starch or fiber on protein digestion and intestinal amino acids in dairy cows. Journal of Dairy Science 76, 2692-2700.

Voigt, J., Schönhusen, U., Krawielitzki, R. \& Piatkowski, B. (1991). Comparison of ${ }^{15} \mathrm{~N}$, amino acid profile, RNA, DAPA and D-alanine as markers for microbial nitrogen flowing to the duodenum of dairy cows. In Proceedings of the 6th International Symposium on Protein Metabolism and Nutrition. European Association of Animal Production Publication no. 59, pp. 71-73. Herning, Denmark: EAAP.

Woodford, S. T. \& Murphy, M. R. (1988). Dietary alteration of particle breakdown and passage from the rumen in lactating dairy cattle. Journal of Dairy Science 71, 687-696. 